\title{
Forma (estructura) y fenomenología en Ortega. Un análisis del "campo visual" en el entorno de las Meditaciones 1
}

\section{(Form (structure) and Phenomenology in Ortega. An analysis of "visual field" in Meditations' milieu)}

\author{
Jesús GonZÁLEZ FiSAC \\ Universidad de Cádiz \\ jesus.gonzalez@uca.es
}

Recibido: 15 de septiembre de 2010

Aceptado: 7 de septiembre de 2011

\section{Resumen}

Los estudios sobre la fenomenología de Ortega apenas han atendido al víncunlo entre forma o estructura y campo del fenómeno. Ortega ha insistido en la formalidad del ámbito de aparición de los fenómenos, que ha vinculado con su radicalidad. La forma del ámbito emerge dentro del campo como un juego de diferencias, de la que el par superficie/ profundidad es el fundamental. En este trabajo vamos a mostrar que la formalidad del ámbito tiene un ejemplo señalado en los análisis del campo visual en el horizonte de las Meditaciones.

\footnotetext{
${ }^{1}$ Este trabajo constituye un análisis preliminar en relación a otros dos. En primer lugar, precede a un trabajo acerca de la meditación orteguiana sobre la luz y la corporalidad, con el punto de mira en sus escritos sobre estética y, sobre todo, en sus trabajos sobre la pintura (en particular sus textos sobre Velázquez). En segundo lugar, puede considerarse como la primera parte de un estudio más amplio acerca de lo formal y lo fenomenológico en Ortega, que se completa con la dilucidación de las "leyes de la estructura formal del mundo".

Las referencias a los textos de Ortega se harán según las siguientes ediciones (para la referencia completa ver Bibliografía):

(OC) Obras completas, diez volúmenes, Madrid, 2004/2010, indicando volumen (en romanos) y página (en arábigos).

(NT) Notas de trabajo, Madrid, Alianza, indicando el número de la nota dada al texto por el editor, seguido de la página.
} 
Palabras clave: fenomenología, forma, ámbito, campo visual, superfie-profundidad, Meditaciones.

\begin{abstract}
The studies on Ortega's Phenomenology have hardly considered the relationship between form or structure of phenomena and their field. Ortega has emphasized the formal condition of the field of manifestation of phenomena, which he has connected with its radical condition. The form of the field emerges inside the field as a game of differences, of which the pair surface/ depht is the most important. In this paper we will show that the formal condition of the field has one of its most important examples in the analysis of the visual field in Meditations' time.
\end{abstract}

Keywords: Phenomenology, form, field, visual field, surface-depth, Meditations.

\title{
1. Fenómeno y estructura. A propósito de la radicalidad del ámbito
}

Como es sabido, Ortega pretende una ontología que pueda llamarse radical. En lo que sigue vamos a intentar mostrar que esta radicalidad es de cuño fenomenológico, advirtiendo para empezar en que esta tesis, que en absoluto es una tesis novedosa, no ha recibido sin embargo suficiente atención en punto a otra consideración, como es la condición formal o estructural de la realidad. Esto quizás tenga su explicación en lo que dijo el propio Ortega acerca de su "replanteamiento del problema del Ser" en ese texto tardío que es La idea de principio en Leibniz, donde Ortega, al tiempo que abunda en que el fenómeno es forma o estructura (el fenómeno es "él por sí sistema"), señala también que éste vínculo de fenómeno y forma (sistema) es, ciertamente, un vínculo inopinado, para empezar para la propia Fenomenología (IX, 150; ibídem, 1119), hasta el punto de tener mucho que ver con su propio avatar con la Fenomenología, concretamente con la paradoja enunciada por el propio Ortega de haberla abandonado en el mismo momento de recibirla (ibídem, 1119). Como si de una relación quiástica se tratara, cuyos términos sólo pueden sostenerse juntos separándose uno de otro.

En todo caso, nuestra tesis es que el fenómeno -y su condición, lo fenomenológico- constituye el índice de la radicalidad. Y que esa radicalidad se juega en la condición formal o estructural del fenómeno, que es lo que podríamos llamar, para empezar y en un sentido lato, ámbito. Por eso la realidad radical es, según la llama Ortega, "el fenómeno de los fenómenos" (VII, 480; en IX 296 dirá que es escena- 
rio). Pero hagamos algunas precisiones sobre el sentido de esta expresión. La realidad radical no es el fenómeno ni un fenómeno, tampoco el lugar de los fenómenos; más bien es el tener lugar todo fenómeno, con independencia por tanto de cualesquiera especificaciones. No es ninguna determinación sustantiva si, en la expresión fenómeno-de-los-fenómenos, tomamos objetivamente el genitivo, pues hablamos de eso que está en todos y cada uno de los fenómenos, exigido por todos y cada uno; pero tampoco es lo segundo, una determinación adjetiva, si entendemos el genitivo subjetivamente, pues la expresión fenómeno-de-los-fenómenos también dice que los fenómenos se deben a y están exigidos por una condición que los cualifica. La escenificación es irrestañable porque, como veremos, funciona como ley. En todo caso, decimos que el ámbito, la naturaleza del ámbito, resuena en la ambigüedad del genitivo, como una indicación de que el ámbito es, de consuno, fenoménico-yradical, que es, esta yunta de adjetivos queremos decir, lo que nos habría que entender cabalmente por "fenomenológico" en Ortega.

Antes de proseguir queremos advertir que no nos vamos a ocupar de la interpretación que a Ortega ha merecido la Fenomenología, ni "la Fenomenología de Husserl" ni la de otros autores con los que Ortega dialoga en el entorno de las Meditaciones. Sobre este vínculo, en este entorno inicial de su trabajo, hay suficientes trabajos y no nos vamos a demorar en él. En todo caso, con la Fenomenología Ortega va a ir saldando cuentas en distintos momentos de su obra, hasta llegar al finiquito que es este texto, sobre todo la nota que lo glosa -la de IX, 1119-1120, texto al que habría que añadir, en este mismo sentido de saldo de cuentas, el Prólogo para alemanes, de 1934. Lo que nos va a ocupar son los tanteos, y también las aportaciones, que el propio Ortega va haciendo en su intento de dar cuenta de la realidad radical; tanteos en los que, a diferencia de la fenomenología al uso -y ello ya debería ser una indicación de la novedad de su camino-, las referencias tanto a la sensación como, sobre todo, al arte, van a ser continuas. Entendiendo por tanto que una pista esencial para dar cuenta de lo fenomenológico en Ortega es la prelación de lo estético -y aún lo hermenéutico-frente a lo eidético.

\section{Consideraciones generales. Positividad y problematicidad del fenómeno. Fenomenología y retórica del fundamento}

Comencemos con unas consideraciones preliminares. Primero. El imperativo de toda fenomenología es que su objeto tiene que mostrarse en cuanto tal y al margen de cualquier supuesto. Podría decirse que la convicción metodológica de la fenomenología se expresa en una suerte de positivismo, digamos un positivimo more orteguiano, que es positivismo absoluto (VII, 485). De hecho, positum es justamente 
eso que no ha sido dis-puesto por un sujeto, es la "realidad primaria", esa "instancia" que el sujeto "no pone, sino que, al revés, le viene impuesto, es algo, por tanto, puesto por sí, lo "positivo" o "dado"“ (IX, 155). En efecto, la radicalidad fenomenológica y positiva del ámbito significa que el haber, el que hay, es eso puesto inalienable. Esto y no otra cosa es el ámbito, el hecho de que hay posición o, si puede decirse de este modo, el hecho del ahí. También pertenece a esta radical positividad del fenómeno el modo en que algo es puesto. Lo que hay se muestra siempre como esto o como aquello, lo que quiere decir que se muestra de cierta manera. Ahora bien, para que podamos decir que hablamos de lo que es radicalmente fenómeno, lo mismo que lo que es radicalmente positivo, no estamos antes dos aspectos o determinaciones distintas. En realidad, el fenómeno sólo es posible porque hay y se da de consuno un cierto modo de haber. Tan originario y por sí es lo puesto como el modo. Nada se muestra si no lo hace de cierto modo, que es donde se descubre la necesidad del ámbito, que sería el modo de la posición.

Segundo. La fenomenología es además un habér-se-las con el fenómeno. Este habérselas es un cierto decir, un decir del fenómeno, del "esto como esto" (un decir también en el sentido específico orteguiano -cf. X, 305 y ss.--, el decir que tiene ante sí cosas que decir). No podemos detenernos en este asunto. Baste con reparar en que de consuno con la determinación el fenómeno en cuanto fenómeno está la del saber del fenómeno. Esto es lo que hace a la Fenomenología verdaderamente radical, que al ocuparse del fenómeno no puede dejar de ocuparse de sí y de ese su habérselas con el fenómeno. Dicho de otra manera, de consuno con la especificación de la "realidad primaria" y al margen de supuestos está la de la "ciencia primera" como ese saber sin supuestos, donde es esa condición an-hipotética, a la postre el ámbito, donde se encuentran precisamente ambas, realidad y saber (o decir).

En todo caso, nos interesa particularmente cómo ha expresado Ortega este vínculo. Un saber se destaca como saber fundamental cuando, dice Ortega, "el tema y la forma [que le ocupan] son una misma cosa" (I, 643). En esta especificación tenemos que se atiende a la condición retórica de cualquier saber, y ello de un modo igualmente rigoroso por lo que hace a la cosa (digamos que no es una retórica meramente formal, que es cuando la forma se convierte en supuesto de sí misma y no en algo de la cosa, cuando es meramente ornamental). Para empezar, se constata que todo saber es un habérselas con algo, con esto o aquello, que es su tema. Pero también se constata, tal sería la lección de la retórica, que todo saber siempre es un decir y que, por eso mismo, es algo singular (o algo que puede ser considerado como singularidad) o que todo saber es un habérselas. Pues bien, este habérselas tiene su propia consistencia, en sí y no en otra cosa, que es lo que haría las veces del tema. Pero esto no basta. Ortega parece atisbar una suerte de retórica fundamental, una retórica del fundamento (genitivo subjetivo), que es la que tiene lugar en las disciplinas fundamentales. Estas disciplinas son las que reparan en que el fundamento es 
ese tema que no puede considerarse al margen de nuestro habérnoslas con él, que es lo que Ortega puede llamar forma. No se trata sólo de que la forma se convierta en tema sino de que la forma que se convierte en tema no es cualquier forma sino el inalienable modo en que nos hemos con cualquier tema (y no ese modo separable, que es el que meramente retórico). Es entonces cuando la noción de "forma" toma un cáriz fenomenológico y no retórico. En general, éste es el sentido de toda la reflexión de Ortega sobre el lenguaje -y sobre el arte- que, como confirmaremos, siempre ha ido de consuno con el problema fenomenológico. Pues, ¿no es precisamente en la obra poética donde no cabe distinguir entre "forma" y "fondo" o "tema" (I, 795-6)? (en lo que sigue volveremos sobre este texto de las Meditaciones).

Tercero. Sin embargo, aquí no termina la radicalidad que queremos poner a la vista. Decimos que es algo positivo que haya fenómenos; también que es algo inalienable el modo en que se muestran los fenómenos, que va de consuno con el modo en que nos hemos con ellos. En realidad, si el tema y la forma se avienen es precisamente porque el tema es esa particular cosa que es un fenómeno. Pero siendo esto así, que los fenómenos, su estar ahí y el modo de ese su estar, también nuestro habérnoslas con ellos, que todo esto sea algo dado no explica todavía que los fenómenos sean algo relevante. Su carácter positivo, que, insistimos, alcanza por igual a su constitución como tema y aún como tema-fundamento, si se nos permite la expresión, este carácter positivo no da cuenta de la relevancia de los fenómenos. El problema de toda disciplina que se quiera fundamental es el problema mismo de la realidad. No se trata de que todo saber tiene un tema, que podría considerarse retóricamente como su problema. Esto es así para cualquiera saber de algo. Cuando estamos ante un saber del fundamento, ha de ser así que lo que sea tema también tiene que ser en sí mismo un tema inalienable, lo que quiere decir que tiene que presentársenos necesariamente como problema. $\mathrm{O}$, si volvemos sobre los fenómenos, el problema fenomenológico fundamental es que los fenómenos se vuelvan relevantes, el problema es su devenir-problema.

Planteémoslo de otra manera. Si el fenómeno fuera lo inmediato sin más, lo que está ahí sin más, no tendría sentido hablar de su relevancia. No basta con reconocer el fenómeno como eso que se da inmediatamente y que cualquiera de las distinciones que recaigan sobre él, como fenómeno físico o psíquico, son sobrevenidas y por ende abstractas. Antes que nada se tiene comprender cómo es así que hay fenómenos. Que algo se muestre supone no sólo un cierto aspecto sino, antes que eso, que hay cierto aspecto, una relevancia, con la que nos hemos también, aunque, y esta es la dificultad, no aparezca nunca y esté obviada por el contenido que se muestra. Como ha señalado Ortega en varios lugares, lo primero es nuestro trato con las cosas y la "actitud natural" es que las cosas se den por descontado. Lo primero y no cuestionado es el tema. El realismo es, en efecto, histórica, pero porque sistemática o fenomenológicamente, la primera actitud o disposición hacia las cosas. Sin 
embargo, el realismo es ya una respuesta; el realismo nace de un problema previo, e incluso como "tesitura o disposición natural" viene precedido por el problema o por la problematicidad misma de lo que hay y de su mostrarse. Pues bien, esta problematicidad, la relevancia misma del fenómeno, tiene que ver con el ámbito. Y el ámbito, por su propia hechura, no es nada más que forma o estructura.

Concluyamos por tanto que las disciplinas fundamentales son relevantes fenomenológicamente si, primero, es un hecho que el tema es forma, si aquello de lo que se ocupan, la imbricación tema-forma, se impone en cuanto tal imbricación, si se impone como la cosa, vamos a decirlo así, y si, segundo, este hecho se impone además como algo inmediato e inalienable, es decir, si este hecho es fenómeno (aunque en realidad, para que la relación tema-forma sea un hecho, y no una posición, tiene que ser un fenómeno). Una disciplina es, pues, fundamental cuando contempla el hecho de la forma y su relevancia como fenómeno. En este sentido tales disciplinas se dice que son disciplinas "sin supuestos", porque no parten de una determinada posición, para empezar la de esta o aquella cosa, sino que están y se ocupan de la imbricación de tema y forma, la cual, y esta es la clave, es el punto de partida de cualquier posición o implicación temática y no una posible elección de tema; como si se encontraran en una suerte de tesitura o disposición anterior a cualquier tema, digamos ante una tesitura o disposición preontológica.

\section{Fenómeno y ámbito. La condición estética del fenómeno}

"Los fenómenos son lo en absoluto patente" (VII, 479). En verdad, constituyen un modo de ser, el "ser fenoménico", que es aquel "cuya consistencia no posee más notas que aquéllas que se nos dan con presencia inmediata" (ibídem, 446). Fenómeno es aquello cuyo ser se agota en ese su aparecer y en el preciso modo en que tiene lugar ese su aparecer. Por eso el fenómeno se define siempre y únicamente por su sola condición de presencia. Una presencia que podríamos llamar redundante. Los fenómenos son lo patente en absoluto: su presencia termina y acaba en la presencia misma. Tan absolutamente patente que incluso el Ser absoluto no puede trasponerse a ella, o, si se quiere, tan absolutamente patente que el fenómeno está en la misma patencia que Dios (cf. ídem). En el mismo sentido se dice de los fenómenos que son inmediatos, desvinculados de cualquier otra cosa, o, si se quiere, que son algo primario (estamos pensando en la contraposición entre conciencia "primaria" y "refleja": IX, 157). En suma, el fenómeno es algo rigorosamente apariencial. Pues bien, esta suerte de pleonasmo -el fenómeno es lo-que-semuestra-en-tanto-que-se-muestra podría ser la fórmula que lo expresa- alcanza por igual al ámbito, que no puede ser nada que sustente al fenómeno. (Esta redundancia ya la hemos comentado suficientemente en la expresión "fenómeno de los fenómenos".) 
El fenómeno tiene en común esta condición con todo lo que tenga un rango o pertenezca a un orden primero. La misma situación del Barón de Castaña a que se refiere Ortega en algún lugar, que tiene que salir del pozo tirando de sí. El fenómeno es eso que se presenta sin más, mientras que lo demás depende de -porque está separado de-otra cosa, si bien esa separación y vínculo no se muestra en cuanto tal. Cabría por tanto distinguir entre el fenómeno en sentido estricto, el "puro fenómeno", o también la pura apariencia (cf. VIII, 183-4), que es aquel que consiste en la mostración de otra cosa, aquel que es transitivamente, a diferencia de eso otro que, por eso mismo, y también en un sentido estricto o puro, es sustantivamente; y el fenómeno en sentido lato, que es cuando se piensa cabe un ámbito y no en relación a un supuesto, esto es, cuando se piensa el fenómeno en sí mismo o en su puro mostrarse, intransitivamente por tanto. Como esto es así, el fenómeno puro es lo que está desvinculado de cualquier ámbito, aquello que no puede concebirse en relación, que es tan solitario como lo sean las cosas de las que depende. En cambio, cuando el fenómeno funciona como entidad transitiva, lo propio de la posición de la cosa es su condición separada. Poco importa que eso de lo que depende el fenómeno ocupe una posición hipotética; lo que interesa es que esta diferencia vincule asimétricamente a los términos, haciendo del fenómeno o apariencia la realidad vicaria y por ende reducible. Por eso, el fenómeno considerado intransitivamente sólo puede guardar un vínculo en el ámbito, que es aquello respecto a lo que no puede haber reducción o dependencia, porque en realidad el ámbito no es nada más que vínculo. La posición del fenómeno, topológicamente considerado, no podrá ser otra que la del ahí (VIII, 443), que, como la luz (a la que se refiere este texto), es ese lugar que carece de "ultranza". Habría una expresión, la de "Trasmundos", que da título a la sección cuarta de la meditación preliminar (I, 768), en donde precisamente el prefijo no significa aquel sentido de tránsito o reducibilidad, y no lo significa porque se dice del ámbito mismo, del mundo, en el que se traza con esta diferencia no una prelación de cosas o realidades sino una distinción de ámbitos, una distinción de "planos de realidad" (I, 769), entre los que podemos movernos pero que, por esa su condición de mundo o ámbito, no son reducibles ni jerarquizables.

Si el fenómeno es lo patente en absoluto, de todos los ejemplos que utiliza Ortega para referirse a esta patencia, el de la luz seguramente es el primero que viene a la mano (lo que no significa ni que sea el único ni el fundamental). Cuando vengamos sobre el análisis del campo visual diremos más de la luz, baste por ahora el siguiente apunte, que nos pone en claro sobre la particular naturaleza de la patencia fenoménica como patencia del ámbito.

En el caso de "la luz, por ejemplo, o sea el conjunto de los colores", el fenómeno de este o aquel color, el color de "el objeto A", se pierde cuando "buscamos tras ese objeto A, tras esos colores ... A', las vibraciones etéreas" (VII, 479). El fenómeno del color, el color como fenómeno, desaparece cuando es referido a una realidad 
de "segundo orden". Como es bien conocido este texto, no vamos a abundar en que esta distinción entre órdenes también lo es entre modos de enfrentar los dos órdenes, la descripción y la explicación. Aquí nos importa que la luz funciona fenomenológicamente lo mismo que el ámbito, y que lo hace precisamente como ese orden en el que no se muestra nada salvo el mostrarse mismo. Para ver esto vamos a servirnos del ejemplo del cristal del Ensayo de estética a manera de prólogo (Ensayo), de 1914.

En este texto se precisa qué es un objeto estético, es decir, en qué consiste eso de que algo se presente estéticamente. En realidad, un objeto estético no es nada distinto de un fenómeno. El objeto estético es ese objeto del que tenemos lo que Ortega llama la "verdadera intimidad", que es aquella que "está a igual distancia de la imagen de lo externo como de lo interno" (I, 670), esto es -tal es lo que se dice literalmente aquí-, aquella en la que el objeto no es en modo alguno imagen. El objeto estético no es, ante todo no es, representación, que participa de esta diferencia interno/ externo. Es algo que se agota en sí mismo, algo cuya calidad es in-comparable, porque no se deja reducir a cualesquiera elementos en los que se pueda descomponer: ni a la existencia material del objeto ni a sus atributos formales (como el color, la forma, etc.). Es todo uno. Por eso dice Ortega que tiene "una presencia de tal suerte plenaria que sólo podríanos describirla con estas palabras: absoluta presencia" (I, 671). Pues bien, algo de lo mismo es el objeto transparente, que es aquel objeto en el que precisamente no se puede separar lo externo, la cosa, de lo interno, yo, sino que se da todo a una (I, 672). Porque, decimos nosotros, lo que tenemos ahí no es sino el fenómeno, el cual, y es por ello que lo traemos aquí, se confunde precisamente con el ámbito.

Para que la transparencia del cristal sea verdadera es menester que dirija mi vista a su través, en dirección a otros objetos donde la mirada rebote: un cristal que miráramos sobre un fondo de vacío no existiría para nosotros. Lo esencial del cristal consiste en servir de tránsito a otros objetos: su ser es precisamente no ser él, sino ser las otras cosas. ¡Extraña misión de humildad, de negación de sí mismos, adscrita a ciertos seres! (I, 672).

Con el cuerpo transparente acontece como con la luz. Cuando deja de funcionar como ámbito para que se presenten las cosas es cuando, efectivamente, deja de haber cosas: "si en lugar de mirar otras cosas al través del vidrio hago a éste término de mi visión, entonces deja de ser trasparente y hallo ante mí un cuerpo opaco" (I, 673). Pero lo mismo cabría decir del fenómeno, que sólo es lo que se muestra mientras no pretendamos buscar otro rango $\mathrm{u}$ orden distinto al de lo que se muestra (en el caso del cristal, yendo más acá, en el de el color, por ejemplo, yendo a la hipótesis de la vibración etérea o a la de la retina). En este sentido bien podríamos tomar como definición de fenómeno/ ámbito la que da del objeto transparente, que es tam- 
bién -repárese bien en esto- la definición del objeto estético: "un objeto que reúne la doble condición de ser transparente y de que lo que en él transparece no es otra cosa distinta sino él mismo" (I, 673).

\section{Interludio fenomeno-lógico sobre la estructura o forma. La conciencia como fenómeno de la diferencia.}

Pero esto todavía no decide qué clase de cosa sea el fenómeno o el ámbito. Si, como hemos dicho más arriba, el fenómeno tiene que volverse relevante, y si este volverse relevante tiene que acontecer fenomenológicamente, tendrá que ser en la forma o estructura misma del fenómeno y del ámbito, es decir, en lo fenoménico mismo, donde se encuentre esta relevancia. Digámoslo también de esta manera: si tenemos que dar cuenta fenomenológicamente de la relevancia, también la relevancia tendrá que acontecer en y como fenómeno o ámbito. Y, según hemos formulado el problema, ¿qué puede ser relevante de algo que es inmediato y obvio?, ¿cómo se puede volver relevante el ámbito en que algo es inmediato y obvio?

Un fenómeno no es un principio, ni una teoria, ni siquiera una opinión [su tesitura es preontológica: J.G.F.]: es una $x$ de quien sólo sabemos, por lo pronto, que es distinta de todo lo demás conocido (VII, 437).

El fenómeno emerge como algo distinto, emerge como diferencia. Ante todo, tal es lo que hemos visto en la sección anterior, no es nada que pueda reducirse a otra cosa, no es algo de lo que dispongamos ya de ciertos atributos (no es algo de lo que sepamos nada), sino que es, si se quiere, el algo relevante, esto es, el simple que hay algo (el algo de lo que, precisamente, no sabemos nada sino sólo que es algo, " $\mathrm{x}$ ", que está ahí). El fenómeno, decimos, es una diferencia. O mejor, es la emergencia de una diferencia, un diferendo vamos a llamarlo. En cualquier caso, una diferencia o diferendo inmediatos (pues cuando hablamos de una hipótesis, también habría una separación y una diferencia pero sólo a cuenta de un procedimiento de mediación). Ahora bien, si el curso de nuestro razonamiento es correcto, el fenómeno no es sólo una diferencia sino que tiene que ser la relevancia misma, la diferencia o el diferendo mismos lo que se muestre, es decir, el ámbito tiene que ser la diferencia misma.

En rigor, el fenómeno de la diferencia, o el fenómeno que es el ámbito, es lo que Ortega llama distancia. No nos referimos a que algo se presente como lejano en oposición a cercano, sino al hecho de que todo lo que se muestra, que el mostrarse mismo, está afectado siempre por una distancia. Todo debe tener una "distancia peculiar" (VII, 752). En la Lección VII de su sistema de psicología Ortega distingue tres distancias entre el sujeto y el objeto. En realidad, sólo la tercera distancia es la fenomenológicamente relevante. Que lo que está presente en la percepción 
constituya un fenómeno, "un aparecer o estar ante mí", de distancia mínima, o que también lo sea el objeto en tanto que representación, "tan positivo como la pura presencia e inconfundible con ella" (VII, 483), es algo que va de suyo; no es relevante, porque va de suyo, decimos, que hay cosas y que hay representaciones de las cosas. Esto es, donde va de suyo toda vez que se trata en realidad de dos proximidades, la de la percepción, es claro, y la de la representación, que aunque suponga una distancia al objeto constituye en verdad la proximidad del sujeto a sí (ante mí y en mí); en todo caso, una proximidad que tiene lugar en ambos respecto de una cosa supuesta. En efecto, "Es un error creer que el aspecto más verídico de una cosa sea el que ella ofrece sometida a una visión muy próxima" (VII, 751), y esto vale tanto para la visión próxima llamada percepción como para la llamada representación (del sujeto a la cosa o del sujeto a sí, como hemos dicho). El error de creer que sólo hay dos distancias, porque en realidad sólo hay dos instancias o realidades. En verdad, según decimos, el error de creer que la distancia se estipula entre estas dos instancias y que, por tanto, se establece como algo meramente relativo donde lo primero es la proximidad. Pues, en realidad, "antes que la proximidad y haciéndola posible tiene que haber la lejanía" (NT, 446, 288).

Como esto es así, Ortega habla de una tercera distancia. Dice -no dice mucho más que esto- que esta tercera distancia es "irritante" (VII, 485). La tercera distancia se refiere a la presencia de algo por medio de "signos y palabras", porque el lenguaje parece que nos sitúa precisamente en otro lugar que no es ni el de las cosas ni el del yo, es decir, en un lugar en el que no hay proximidad alguna ni, por tanto, transición o reducción. La mención es un lugar básicamente in-transitivo, pero no porque haya sólo una instancia, sino porque no se decide por ninguna de las dos instancias. O mejor, porque se decide precisamente por la diferencia o el entre. Por eso, mientras que las otras dos distancias / proximidades se presentan en realidad como cosas mostrencas, como algo que es "por sí mismo intransferible" (VII, 484), la mención queda ligada a la figura de la metáfora, que significa literalmente transferencia. La metáfora es también la figura con que podemos dar cuenta del objeto estético, que, como hemos dicho en lo anterior, no es nada distinto del fenómeno mismo (y, así, dice Ortega que el fenómeno, el mostrarse de algo en cuanto es algo, es "metáfora esencial": II, 682). En la metáfora tiene lugar una particular mostración que es el trasparecer-se: algo se muestra pero a costa de no hacerlo. Como el cristal y la luz, que sólo están presentes a costa de perder sus cualidades esenciales, es decir, a costa de des-realizarse. Porque, en efecto, nada de lo que se sostiene metafóricamente, el ciprés, la llama o el espectro, es lo que es. Las semejanzas entre ellos son, como dice Ortega "inesenciales". La metáfora sostiene en verdad la relación, la di-ferencia, entre los términos, que no significan cosa alguna sustantiva. La metáfora, dice Ortega, "vive la conciencia clara de la no-identidad" (I, 674). El "linaje de asociación" (VIII, 187) de la metáfora no es pues la contigüidad (infra), 
que sería el linaje de una relación entre identidades, sino el de una relación que se impone a los términos y los priva de su esencia. Una relación distante o, como dice en otro lugar, una correlación estricta o absoluta (irreducible). La metáfora es el fenómeno (lingüistico) de la relación.

En todo caso, y con independencia del ámbito (en la metáfora, el del lenguaje), el fenómeno consiste en la relación entre dos términos irreducibles, o en la diferencia o en la estructura o forma de esa diferencia, tanto da. Por eso, siendo el fenómeno de esta manera, la genuina fenomenología tiene como "imperativo metodológico" insistir "en lo diferencial de las cosas, impidiendo su nivelación" (VII, 455). Pensemos que, aunque en algún lugar dice Ortega que la estructura es "una cosa de segundo grado, ..., un conjunto de cosas o simples elementos materiales, más un orden en que esos elementos se hallan dispuestos" (I, 781), la prelación fenomenológica de la estructura estriba en que no es una mera adición para lo comprendido en ella sino que es lo que la habilita para las cosas. Es decir, son "las cosas trabadas en una relación", y no la relación misma, las que "forman una estructura" (I, 782). En verdad no hay cosas aisladas y su realidad, la estructura y la relación, es precisamente eso que habilita (idem). Lo mismo cabría decir de la forma, que considerada como un esqueleto vacío no es nada más que algo formal (la base de alguna clase de "formalismo": VIII, 178), si bien, pensada como vínculo, habilita los términos que guardan relación.

Pero sigamos con el fenómeno. Piénsese que la distinción entre fenómeno físico y psíquico que ocupa a las Investigaciones psicológicas es una dilucidación fenomenológica sobre el valor y el sentido del fenómeno. Aquí no se trata tanto de la oposición entre fenoménico o apariencial y real o hipotético (VII, 445 y ss.), sino de pensar una diferencia genuinamente fenoménica, esto es, de pensar cómo se pueden distinguir los fenómenos. Por eso el resultado es, si puede decirse así, paradójico. Podría parecer que, llevados por la distinción inmediata entre interno y externo, los fenómenos psíquicos serían los fenómenos internos mientras que los físicos serían los externos. Con independencia de qué cosa fuera o permitiera reconocer lo interno o lo externo, Ortega recuerda que la distinción misma es fenomenológicamente insuficiente. Concretamente, porque no es una distinción que determine positivamente los fenómenos, pues tan sólo dice del fenómeno externo que es lo nointerno y viceversa. Esto es, porque es una distinción meramente lógica. En efecto, "una diferencia fenoménica no puede nunca reflejarse suficientemente en un concepto negativo: el fenómeno es siempre algo positivo, nunca un no-ser otra cosa" (VII, 447). Pero, ¿y qué supone esto? Para empezar, que no estamos ante la distinción entre ser fenoménico y ser real; lo interno no es lo hipotético o supuesto. Por eso, si tenemos que poder hablar de fenómenos externos e internos tiene que poder haber algo que reconozcamos positivamente (nunca lógica o conceptualmente) en cada uno de ellos. En el caso de los fenómenos externos la sensación nos propor- 
ciona ya suficientemente esta condición apariencial e inmediata. En el caso de los fenómenos internos, sin embargo, y en un modo paradójico, va a ser la conciencia.

El subjetivismo moderno tiende a ver -en lo que sería otra clase de disposición o tesitura natural, la que sigue de modo consecuente, pivotando sobre su mismo supuesto, al realismo- "antes que la cosa al sujeto que piensa" (VII, 449). Por eso, como el sujeto que piensa se ha convertido en otra cosa, bien que anterior o prevalente, todo aquello de lo que es capaz, digamos "lo psíquico", se convierte igualmente en algo de ese sujeto. Es decir, se convierte en fenómeno en sentido estricto. Ahora bien, de la misma manera que no hay vibraciones etéreas sino el fenómeno del color, también en el caso de la conciencia "lo único que en ese momento aparece ante mí es ... el color" (VII, 450), y no mi conciencia por un lado y el color por otro. La conciencia-del-color, que parece sugerir que el color es un término, y por ende algo distinto y separable, de la conciencia -sugerencia que deriva de la gramática del genitivo, a saber cuando funciona transitivamente, aunque también esta misma gramática, cuando funciona intransitivamente, nos puede revelar la unidad del fenómeno, como hemos visto ya-, no es algo distinto del estar-percibiendo-yoel-color. En verdad, lo único que hay es el fenómeno mismo de mi percepción, o "mi percibir ... verificándose" (VII, 451), esto es, mi percibir especificándose "hasta las últimas individuaciones" (idem). Esta singularidad es la que hace irreducible al fenómeno psíquico y a la conciencia, cuyo ser fenoménico se revela como un particular ser ejecutivo (según la expresión de Ensayo), y es donde hay que buscar la inalienabilidad del fenómeno. El fenómeno es inalienable porque es absolutamente -porque todo en él es-concreción.

Pero no es sólo esto lo que nos interesa de la conciencia. Además de su condición de fenómeno inalienable, lo que hace que la conciencia se vuelva fenoménicamente relevante es el hecho de que constituye precisamente una relación. La "interpolación o intromisión" que supone el subjetivismo y que consiste en que la conciencia se pone como supuesto entre el fenómeno y la cosa anula precisamente lo que es propio del fenómeno psíquico. O habría que decir mejor, lo que es propio de cualquier fenómeno, que es su condición de diferencia o relación irreducible. La intencionalidad, término que utiliza Ortega con toda precaución (nos referimos a VII, 493), señala el hecho de que hay un fenómeno, el fenómeno de la conciencia, que consiste en sí mismo en una trabazón entre dos elementos (VII, 466 y ss.), entre uno mismo y otra cosa: "la conciencia no es una cosa que se refiera a otra sino que es el referirse mismo" (VII, 493; el subrayado es mío). O, como dice en otro lugar, la conciencia "jamás se nos da en solitario" (VII, 657). Por eso la intencionalidad está vinculada al juicio. El juicio es la forma misma de esa trabazón, precisamente porque constituye una particular forma de relación o de vínculo. Una relación o vínculo que es originario y que no sobreviene a los términos de la misma. 
Del juicio nos interesan al menos dos cosas. Primero, cómo la cópula da cuenta de esta particular trabazón que hay que pensar en el fenómeno y en el ámbito (teniendo en cuenta que el ser es otro nombre para el ámbito). Segundo, cómo expresa la inalienabilidad del ámbito en el modo de "ley" o "imperativo".

El vínculo entre juicio y relación es un lugar común en la Lógica. Lo que Ortega viene a recordar es que el juicio es, en sí mismo y fenomenológicamente, la forma de la relación. La forma de la relación, o el juicio formalmente entendido, es la forma de la predicación. "Ser A" o "ser B" "son [expresiones] insuficientes, son incompletas" (VII, 471-2), dice Ortega, porque "ser A" es en realidad "ser C-A" y "ser B", "ser C-B". Estas expresiones contienen, pues, "la perpetua referencia y alusión a algo distinto de ellos" (VII, 471). Es decir, los juicios albergan en sí mismos su propia condición de remisión a otros. Que es, como acabamos de ver, el mismísimo ser de la conciencia y el ser del ámbito (como "el aire" que nos envuelve: VII, 657). Sin embargo, a nosotros no nos interesa sólo constatar que estamos ante la misma forma sino si y cómo el juicio se revela él mismo como fenómeno. Esto es lo que encontramos en la condición legal o imperativa de la forma-ámbito.

\footnotetext{
Una sola relación puede, en rigor, establecerse entre dos fenómenos puros; pero esta relación no será relación de juicio, sino otro puro fenómeno, en que la asociación de elementos se produce por pura contigüidad en el acto de conciencia, no por ninguna apelación a una cualquiera legitimidad. Este linaje de asociación es el que acontece en la llamada "metáfora (VIII, 187).
}

Recuérdese que el "fenómeno puro" es precisamente el fenómeno cuyo ámbito es la "conciencia pura", es decir, el fenómeno sostenido hipotéticamente por la "cosa "conciencia"“ y que por tanto es el modo espúreo de fenómeno o, si se quiere, el fenómeno fenomenológicamente no-relevante. Lo que nos interesa de este texto es que recuerda que el vínculo que podemos considerar formal, el vínculo que establece el ámbito, es precisamente aquel que no es sobrevenido. Los fenómenos puros, como "Veo una mesa negra", "Veo una mesa blanca" (VIII, 187), se aúnan en una misma conciencia, pero como esta conciencia constituye una instancia sustantiva, se aúnan como este fenómeno - o este acto, tanto da-de conciencia, este fenómeno de conciencia, etc., donde prima por tanto la identidad de la instancia, frente a la diversidad y cualidad del fenómeno, identidad que sólo permite poner los fenómenos unos junto a otros, contigüa o adjetivamente, esto es, que sólo permite asociarlos. Por contra, cuando hablamos del vínculo del juicio estamos ante un modo de relación interno y constitutivo, esto es, ante una forma o estructura que, por eso mismo, es inalienable. El imperativo de la distancia a que nos hemos referido antes va de consuno con la ley de la relación, porque es su otra cara. La necesidad de la profundidad sobre la que ahora vendremos es la necesidad del ámbito, que aquí llama "legitimidad". 
Es lo mismo que nos encontramos en el campo visual, como en general en cualesquiera percepciones, donde no se dan nunca separadamente sino siempre individuadas en el esto concreto. Así, percibo siempre color y forma (de una piedra), lo mismo que olor y color (del mar), etc. (VII, 451) (al igual que, como vimos en la obra poética, van de consuno tema y forma). En el caso del color se nos revela una ley fundamental del campo visual, a saber, que no se puede dar el color sin extensión. Esto es, se nos revela que estamos ante una forma o estructura, ante un vínculo que es originariamente sintético. El ejemplo de esta ley, de que "no hay color sin extensión sobre que aquél se extienda" (I, 629), es desarrollado por Ortega precisamente recordando la deducción o justificación kantiana de los juicios sintéticos que, como sabemos, no es sino la justificación de la condición sintética del juzgar. Así, ni la ley "se apoya en mi visión de ahora en cuanto ésta es un hecho" -la ley no es empírica-, ni "el concepto "color" y el concepto "extensión" por sí mismos no darían nunca esa ley" (idem) -la ley no es una consecuencia lógica inmediata. El color es, podemos decirlo así, un objeto estructural (VII, 468), uno más de los fenómenos donde se revela la condición co-significativa (VII, 470-2) de nuestro habérnoslas con las cosas. El objeto estructural es un objeto trabado en el que siempre y al mismo tiempo se revela una forma o estructura, lo que quiere decir, un ámbito, y por eso también son llamados "objetos totales" (VII, 468). El objeto estructural es, lo mismo que el objeto estético, un fenómeno.

\section{Diferencia y relevancia fenomenológicas. La conciencia como problema}

Ahora bien, ¿cómo se puede volver relevante la relación?, y también, ¿por qué puede parecer que lo primero es que quede obviada? Cuando tenemos una hipótesis es cuando se oculta el fenómeno y la relación. $\mathrm{Si}$, como hemos señalado, de alguna manera las dos interpretaciones que han dominado el conocimiento y la verdad, la realista y la idealista, han sido igual de abstractas e hipotetizadoras, ¿cómo se gana el fenómeno en su complejidad y estructura?, ¿acaso desde un trabajo eidético, dicho a la manera husserliana? De ser esto así, si estuviéramos ante el producto de una acción sobrevenida, en verdad no podríamos hablar de fenómeno. Como hemos visto, de los análisis y las distinciones sobre el ser fenoménico y el ser real Ortega critica que busquen dar con una definición lógica, cuando esto no aporta la verdadera diferencia, que es aquella se que da inmediatamente en los fenómenos como fenómenos. Por lo mismo, la relevancia del fenómeno tiene que ser una relevancia positiva (un particular "deslinde": VII, 451), desde o cabe el mostrarse mismo. Pero, ¿cómo?.

Cuando hemos visto la metáfora ha quedado claro que si la diferencia puede mostrarse en ella es justamente a cuenta de que no se muestren las cosas en su ser 
sino su relación. Lo que se gana en esa desrealización es precisamente la relevancia del fenómeno, es decir, lo negativo del fenómeno tiene que servir a su emergencia y no puede dejar de mostrarse en él. El fenómeno sólo se podrá ganar de un modo negativo pero no lógico, digamos como resistencia y aún como resistencia fenomenológica. Ortega habla en este sentido de "fenómeno incoercible" (VII, 437). Esto es lo que pasa cuando el fenómeno se muestra en cuanto tal pero no como negación de cualquier otro sino como positiva afirmación, donde la relevancia consiste en esta resistencia a ser reducido. Todo lo contrario de esas otras diferencias que, por ser contradictorias, son a la postre meramente relativas (VII, 448), es decir, diferencias que no alcanzan un anclaje fijo y que sólo remiten -o resuelven-indefinidamente.

Pues bien, lo que sucede para que haya relevancia es que algo se tiene que mostrar como irreducible. Ese algo, que entonces es llamado fenómeno, se presenta como un problema, porque no hay nada, no hay otro algo, que pueda ponerse a su base o su-ponerse, que es lo que le daría fin y comprensión a lo que hay delante. "No hay, pues, que recurrir a objetos sutiles y metafísicos para indicar que poseen las cosas maneras diferentes de presentarse" (I, 766). En este sentido hemos contrapuesto problema a hipótesis. Lo propio del fenómeno es que se presenta con diferencias que son evidentes, lo cual quiere decir -en un sentido fenomenológico noclásico- que son diferencias que no pueden reducirse o que no pueden proseguirse indefinidamente. Y no pueden reducirse, y esta es la clave, porque su di-ferendo no es meramente lógico, ni mediato, sino fenoménico, es decir, porque no se muestran como tales como resultado de una negación sino más bien como el precipitado de una carencia o falta, que es ese tipo de negación insustituible (loci varia).

Pensemos que en la relación entre la hipótesis y lo sostenido por ella, hay una reciprocidad, propiciada por la forma lógica que la sostiene, que en realidad la reduce a un vínculo de equivalencia entre ambos, a una fórmula de identidad o no contradicción, y que, así, la elimina como relación o como remisión -estamos pensando en la equivalencia entre " $p$ implica $q$ " [toda relación se expresa como implicación] y "no ( $p$ y no $q)$ ". En realidad no hay nada más que una tautología. La cosa es sustancia y el ahí es subterráneo, siendo ese sub- o ese hipo- un encubridor de la diferencia inmediata de que hay cosas. O dicho de otra manera, lo propio de las cosas es que tienen un ahí zanjado mientras que los fenómenos sólo tienen un ámbito.

La relevancia es una suerte de fracaso, pero el fracaso anterior y constitutivo de todo fenómeno, de la hipótesis y de la mediación del pensar. El fracaso que pone en movimiento el pensar, el ensayo inacabable de resolver el problema formal de lo que hay. Por eso, como vamos a ver a continuación, no hay en verdad fenómeno si no hay ámbito. 


\section{El ámbito como estructura de diferendos. El juego superficie-profundidad en el campo visual}

Pero volvamos a las Meditaciones. Repárese en que lo que suscita en realidad la meditación es el reconocimiento del ámbito (o el reconocimiento de que hay fenómenos, tanto da). Lo que se muestra primero en la Meditación preliminar, es "El sitio [que] se llama "La Herrería"“ (ibídem). Es el "sitio" o el "lugar" eso que se vuelve relevante. Pero, ¿cómo se puede mostrar un ámbito? El ámbito se muestra, vamos a decirlo así, como un diferendo. Para empezar, el ámbito se muestra como algo que no se puede nivelar (que es lo sucede cuando los fenómenos son la apariencia de algo). Por tanto, como un lugar o un sitio donde hay-y-no-hay cosas, como el dónde que, de consuno -en lo que sería la condición fenomenológica propia del ámbito-, puede estar o puede no estar ocupado. Decimos que se trata de un diferendo porque hay cosas en torno y porque también, como parte de ese entorno, hay un vacío (el no-estar de antes). En suma, un diferendo en sí o formal, porque ninguno de los términos puede serlo absolutamente: ni hay lo absolutamente lleno ni hay lo absolutamente vacío. Pero el diferendo no se limita a este doblez. Para que el fenómeno se muestre o se vuelva relevante el diferendo es algo que tiene que acontecer, concretamente es algo que tiene que acontecer como problema. Este acontecer, el devenir fenómeno como lo hemos llamado, nos pone ante el particular modo de presentarse lo que se muestra.

Ortega se sirve de una serie de distingos para caracterizar el juego de este diferendo. "Profundidad" y "superficie", "invisible" y "visible", "latente" y "presente" marcan oposiciones que no deben ser entendidas, so pena de perderse su valor fenomenológico, ni como oposiciones meramente lógicas, aunque en el diferendo tiene que haber negación; ni como términos complementarios que encerrarían un juego de reciprocidad, aunque el diferendo supone que hay un vínculo. Lo propio de todo fenómeno es que hay algo que no se muestra; ésta es la negación constitutiva que Ortega apunta como "cualidad positiva" (supra). La negación que comporta esta diferencia es constitutiva porque en ese no-mostrarse tiene lugar algo que es necesario para la mostración misma; o, si se quiere, porque también este no mostrarse tiene que "presentársenos", y tiene que hacerlo, so pena de perderse positivamente para el fenómeno, "en tal forma que no pierda su calidad" (I, 767). Lo que en verdad se muestra es, así, algo esencialmente remiso. El fenómeno es esencialmente remisión, algo que di-fiere y re-envía a otra cosa y a otro lugar (es metá-fora, como vimos). El fenómeno en su mostrarse es algo que abre el lugar, que lo expande. Este es el juego de superficie/ profundidad. El que la profundidad -pero lo mismo podría decirse de lo invisible y de lo latente- "padece el sino irrevocable de manifestarse en caracteres superficiales" (idem); "La dimensión de profundidad ... se presenta siempre en una superficie" (I, 770). Porque la manifestación o mostración misma, 
el fenómeno en acción, es precisamente la expansión misma, que es en lo que consiste el ámbito. Una "distensión virtual", como la llama luego (I, 768), para referirse al hecho de que eso así expandido no es un espacio real sino la posibilidad misma de diferendo y de mostración. Cuando algo se muestra, cuando se destaca, dice Ortega, ese algo "se liberta y expansiona" (I, 782).

Pero la negación constitutiva no se acaba en el diferendo superficie/ profundidad. También tienen que poder distinguirse las cosas entre sí, digamos las superficies qua superficies. "entre las cosas hay, por lo pronto, sus límites" (I, 783). Es claro que esta negación parece ser la más obvia. Las cosas, precisamente en tanto que cosas, como realidades mostrencas, consisten y, porque consisten, también resisten o-como dice Ortega un texto lejano a estos que estamos viendo- no son "interpenetrables" (X, 184). Ahora bien, el límite, lo mismo que la estructura, no puede ser algo sobrevenido. Ahora no se trata de tener en consideración la distinción entre las cosas y su sentido, o entre los sentidos, pasivos, y el concepto, activo (porque la profundidad, como se sabe, es dilucidada como la ejecución del órgano del concepto, del concepto como órgano). De hecho, debemos advertir que estamos evitando cuidadosamente todo lo que en las Meditaciones pueda sacarnos del ámbito o del campo de fenómenos. Y cosas que remitan a fuerzas o a potencias, con independencia del saldo que arrojara un análisis más detenido de las mismas (porque intuición y concepto demuestren ser a la postre también una suerte de diferendo), nos sitúan precisamente en esa clase de distinciones que estamos intentando evitar.

Tenemos que poder reconocer los límites, al igual que hemos hecho con la estructura o forma, gracias al propio sesgo fenomenológico visual del ámbito. Pensemos que "Si no existiera más que un objeto aislado y señero, sería ilimitado" (I, 783). Pero el ámbito no es un objeto de esta clase. El ámbito no es una cosa; lo mismo que el ser, es una cuasi-cosa (loci varia). Ahora bien, por eso mismo, si la profundidad distiende y vuelve relevante la superficie, esta su virtualidad-de la que podríamos decir que seguramente es el significado rigoroso del prefijo "cuasi" que Ortega utiliza en muchos lugares-, que es la virtualidad de la estructura, esta virtualidad, decimos, está limitada en sí misma a la presencia de la superficie. Por eso no hablamos nunca de profundidades y sí de superficies. Es así que nos encontramos con que hay cosas, cosas demasiado concretas si puede decirse de este modo, que son aquello con lo que nos hemos: el Monasterio, el collado, el boscaje, el robredal y el fresnedal, los colores y las estaciones, ... (I, 763). Es decir, es así que la profundidad también se destaca respecto de las superficies y los fenómenos como lo indeterminado (que no como lo ilimitado). Esto, al fin y al cabo, es lo que Ortega quiso expresar casi cuarenta años después con la primera y segunda leyes estructurales del mundo, aquellas que dicen que son pocas las cosas presentes pero innumerables las cosas latentes, precisamente porque -las leyes estructurales se engarzan dinámica y funcionalmente- siempre que tenemos algo presente lo tenemos sobre un fondo de 
muchas cosas latentes (X, 177). El límite es el aspecto del fenómeno que da cuenta de la indeterminación del fondo, el aspecto que destaca fenomenológicamente de la multiplicidad de cosas concretas.

Lo que se revela en la mostración no es otra superficie, ni siquiera algo mismo de la superficie. Lo que viene a mostrarse es la mostración misma, el diferendo entre superficie y profundidad. En efecto, "El mundo profundo es tan claro como el superficial" (I, 768) porque están equiparados fenoménicamente. Y esto debe entenderse literalmente: no es que se muestre otra superficie, lo que se muestra es la apertura misma o, como lo llama Ortega en estas líneas, "el mundo" (I, 765). Ahora bien, el ámbito, el mundo, no se muestran sin más; lo que se revela es la forma misma y la forma se destaca como diferendo. Ortega aclara que este destacamento de la forma, el di-ferendo o dis-tensión, toma la figura de la alusión. Ahora bien, el modo en que se marca la alusión nos revela algo de la negación. Dice Ortega que la profundidad de algo es "lo que hay en ello de reflejo de lo demás, de alusión a lo demás" (I, 782). El modo en que se destaca estructural o formalmente algo dentro del campo visual es el de una particular repulsión. Pero no de la cosa por la profundidad, que se muestra como la no-cosa, sino de la profundidad en la cosa misma, que parece repelerse a sí (esto lo confirmaremos cuando veamos el análisis de la luz y del reflejo). O de la cosa que, si se quiere, di-fiere de sí.

El bosque es un lugar particularmente fecundo para comprender el juego de profundidad y superficie porque él mismo es un conjunto formado básicamente por objetos parciales, si puede decirse de este modo, objetos en los que siempre deste1la, en este modo de la alusión, el todo (el juego de parte y todo es otro de los que se sirve Ortega con frecuencia para significar esta forma o estructura de alusiones). El fenómeno no está dotado de plenitud; también hay algo en el fenómeno que es carencia o falta, algo que es hueco. En esto la profundidad se sigue mostrando como remisión, pero ahora en el sentido de un apocamiento o de especie de suspensión de lo que se muestra. Porque, tanto como hay mundo, nada de lo que se muestra es el mundo. El mundo es lo in-mostrable en cuanto tal. Lo mismo que la luz o que el ser, es aquello que falta, pero no sólo accidentalmente: "es la falta o defecto absolutos" (VIII, 443). Como esto es así, y siguiendo con el diferendo y con el juego del diferendo que queremos dilucidar, entre superficie y profundidad no tiene lugar una contradicción meramente relativa (supra), sino una suerte de dinámica de la privación (VIII, 443-4) (y que habría que vincular con el problema de la diferencia intensiva, que es una de las claves que nos presenta la fenomenología del campo visual, aunque en este trabajo no nos ocuparemos de esto). 


\section{Visibilidad e iluminación del campo}

Sigamos con el campo visual y con su presencia en las Meditaciones. Lo primero que nos encontramos en la presentación del ámbito es, por lo que hace al color, los cambios cromáticos que se aprecian en La Herrería. Como se trata de hacer relevante algo así como el "sitio" o el "lugar", según hemos apuntados antes, el color sirve, precisamente con toda la intensidad y distinción con que se encuentra en las cosas que llenan el bosque, como color característico, diríamos, también como color tópico y fijado (el verde oscuro de la espesura en verano y el verde esmeralda de la hierba en primavera, por ejemplo) para apuntalar diferencias en el paisaje. Se vuelve así relevante que hay un lugar de los colores; o que los distintos colores muestran qua distintos, que la misma cosa presenta distintos aspectos; es decir, se vuelve relevante el fenómeno de una diversidad de aspectos, que lo que hay es una diversidad de aspectos. Pero el cromatismo no es lo que interesa en realidad a Ortega, sino la luz -y sus grados- que es el índice fenomenológico de una tal diversidad y que nos permite reconocer el ámbito.

Cuando nos hemos referido a la retórica del fundamento hemos apuntado que el haber de los fenómenos y nuestro habérnoslas con ellos era algo inalienable. El fenómeno no es sólo lo que se haya, como dice Ortega en algún lugar, sino también e igualmente lo que hallo (cf. VII, 448). La inalienabilidad del fenómeno se expresa como el hecho de que todo lo que se muestra va de consuno con un haberse con lo que hay. Como importa que el ámbito sea una estructura o forma, el fenómeno lleva consigo tanto ese su haber como el haber-nos (el ser es un "ser-nos"), sin que puedan en verdad distinguirse uno de otro. La figura que toma este aspecto en la estructura o forma del ámbito es la del centro (ya hemos visto esta expresión en Meditaciones).

Pues bien, como esto es así, cuando hablamos de la luz como ámbito no hay que pensar tanto en la luz como en la visibilidad, que sería el nombre para la relevancia del fenómeno respecto a la luz. Hablamos así del fenómeno visual. Consideremos, por ejemplo, la "tercera dimensión" de que habla Ortega (I, 766). La tercera dimensión constituye la negación absoluta de lo visible; no es aquello que no es visto porque no hay luz, sino aquello en donde no puede haber luz, pero, y esta es la clave, cuando y en tanto que hay algo visible. De la misma manera, la profundidad es lo otro de la superficie, como eso que no-es superficie en un sentido formal, es decir, no es simplemente lo que podría ser superficie sino aquello que de consuno con la superficie no es superficie y hace falta para que haya superficie.

Ortega explica esto de un modo muy pregnante desde el punto de vista fenomenológico con el ejemplo de la transparencia (ahora nos referimos a un texto de las Meditaciones). No se puede anular esta tercera dimensión a cuenta de desglosar por capas el cuerpo de tres dimensiones. Si consiguiéramos un cuerpo de dos dimensio- 
nes, es decir, si consiguiéramos una superficie pura, además de tener un paradójico cuerpo sin grosor no habríamos conseguido nada. Literalmente nada, tampoco una superficie. Una superficie de dos dimensiones es una suerte de oxímoron, cuya paradoja muestra la verdadera naturaleza de esa tercera dimensión, que no es otra que la formal incapacidad de la luz de alcanzarlo todo, la inalienabilidad, lo que también quiere decir la necesidad, de su límite. La "perfecta trasparencia" es, dice Ortega, lo mismo que "nada" (ibídem). Trasparente es aquello a través de lo que miramos a otra cosa, pero en rigor no es nada (I, 672). A todo lo que se muestra pertenece la tercera dimensión y, con ella, la invisibilidad, o mejor -si es que queremos dar cuenta de algo así como devenir del fenómeno-la ocultación, "la formal "ocultación”“, como la llama Ortega en otro lugar (NT (147), 111), que no es otra que la ocultación del ámbito.

En verdad, la luz no es nada. Es el medium puro, si puede decirse de este modo. Por eso no hay en realidad luz sino claridad, o habría que decir más bien, claridades. Porque "No hay una claridad absoluta; cada plano u orbe de realidades tiene su claridad patrimonial" (I, 777). En este sentido la claridad no se opone a la confusión. Cada plano tiene su propia claridad o iluminación (I, 777). No hay planos oscuros, por lo mismo que no hay planos confusos. Los colores puros tampoco existen; sólo hay colores desteñidos en mayor o menor grado y en ese desteñimiento se alberga su profundidad (I, 769). Son los colores que Ortega llama "colores aparentes, fenomenales" (VII, 479). En alguno de sus textos sobre Velázquez, Ortega señala que el brillo, cuando la superficie devuelve pura luz, cuando es una superficie saturada si puede decirse así, es precisamente un momento de absoluta opacidad en el que no se muestra nada. No es por tanto un momento de profundidad, pues falta precisamente claridad y, con ella, el grado y el matiz que permiten que la superficie sea superficie. La superficie brillante es otra forma de pura superficie y, por ende, nada. De hecho, el color puro se sitúa precisamente de parte de los reflejos. Los reflejos "no son de ella", de la cosa. Si son puros es porque son irreales. "el reflejo es aquella nota de color, de luz, que no lleva en sí forma ninguna de cosa, que es puro color informe" (II, 435). Por eso, porque carece de forma, "no acertamos a ordenar nuestra visión de él y suele producirnos deslumbramiento" (II, 436). "Y no es, ..., por el exceso de luz" (VII, 530), sino porque no podemos localizarlos. "Lo azul y lo rojo son diferentes, pero esta su diferencia cae fuera de cada uno de ellos" (VII, 317). Por eso, a falta de los matices, necesitamos de otra cosa, por ejemplo el marco, pero también el escorzo, con respecto al que ubicarlos para así, en la diferencia, poder percibirlos. Por eso necesitamos el campo (visual). 


\section{Referencias bibliográficas}

Ortega y Gasset, J. (1994): Notas de trabajo, ed. José Luis Molinuevo, Madrid, Alianza.

Ortega y Gasset, J. (2004-2010): Obras Completas, diez volúmenes, Madrid, Fundación Ortega y Gasset/ Taurus.

Jesús González Fisac

Departamento de Historia, Geografía y Filosofía

Universidad de Cádiz jesus.gonzalez@uca.es 